\title{
An AI solution for Soil Fertility and Crop Friendliness Detection and Monitoring
}

\author{
Varshitha D N, Savita Choudhary
}

\begin{abstract}
Agriculture is the main occupation of India and more than $50 \%$ of people are dependent on agriculture. Research on agriculture will strengthen the economic growth of the country. Technologies play a vital role to bolster the agriculture. Since soil is the main fount of agriculture, there is a need for significant approach to help the farmer to test and monitor the soil and its properties, which will boost the fertility of the soil thereby intensifying the crop growth, also if crop recommendations are imparted to farmers in a proper way, crop yield can be enhanced to meet the growing demand for the food. Proper awareness on soil will benefit the farmers to grow the right and healthy crop. To overcome the disadvantages of traditional soil testing practices we are proposing an approach which has Deep learning, an artificial intelligence(AI) technique and IOT features. This helps in getting fast and accurate result. Soil fertility can be calculated by parameters like $\mathrm{pH}$ level, temperature, Moisture content of the soil,temperature, humidity and NPK(nitrogen, phosphorus, and potassium), organic matter, carbon level. Weather and Climatic conditions along with the soil parameters will help to evaluate the soil fertility. The lacking nutrients in the soil and needed nutrients/fertilizers to boost the soil fertility can be suggested to the farmers and also the crops which can be suitably grown from the given soil sample and nutrients required for all the recommended crops to enhance the yield can be suggested to the farmers.
\end{abstract}

Keywords: Artificial Intelligence, Deep learning, Crop recommendation, NPK, Soil fertility.

\section{INTRODUCTION}

\begin{abstract}
A.Basic Notion
Agriculture is the biggest economy sector of our India and contributes more to the socio-economic development of India. For more than $50 \%$ of Indian population, agriculture is the source to fulfill the livelihood. Farmers strive very hard right from the time they sow to the time they reap. The traditional methods of agriculture need to have modern touch to increase the productivity as to meet the growing population and market. The innovations using technologies are reaching the farmers to serve them in monitoring the crop growth , increase their yield \& productivity, hence precision agriculture is the trending field to work for the researchers in India. There are several researches going on across the globe to promote precision agriculture and dwindle the burden of farmers.
\end{abstract}

Manuscript received on December 25, 2020.

Revised Manuscript received on January 08, 2021.

Manuscript published on February 28, 2021

* Correspondence Author

Varshitha D N*, Department of CSE, Sir MVIT Bengaluru, obtained Mtech (CSE) from VTU, Karnataka

Dr. Savita Choudhary, Associate. Professor Department of CSE, Sir MVIT, Bengaluru obtained PhD Bhagwanth University, Ajmer.

(C) The Authors. Published by Blue Eyes Intelligence Engineering and Sciences Publication (BEIESP). This is an open access article under the CC BY-NC-ND license (http://creativecommons.org/licenses/by-ncnd/4.0/)

The emerging technologies like IOT, robotics ,Sensor networks, cloud networks, machine learning and many more things are stepping into farmer's life and trying to ease his work. Soil plays a vital role for agriculture, important nutrients in the soil will result in the crop growth. If nutrients are soil, more fertile will be the land to grow healthy crops hence more yield will be produced. Soil properties like NPK(nitrogen, Potassium, Phosphorous), pH, moisture, , organic matter, carbon content, humidity along with seasons/weather or climatic conditions and type of soil are important to be considered for plant growth. Maintaining and monitoring soil fertility and its nutrients becomes the prioritized task of agriculture. There needs a lot of researches to enhance the soil fertility and crop predion practices in Agrarian country like India. The application that has to be developed for soil testing need to be robust, cost friendly and user friendly to reach the farmers. The growing environmental changes have to be then care to make the application more successful, since there are many ideas proposed the practical implementation is the question of concern . Cost for deployment is also an issue for unsuccessful implementation. There are various research works happening to come up with the solutions for managing soil and to increase its fertility, some are proposed ideas and rest are prototype systems which need to be implemented in future after successful result showcase. Robotic seed sowing and harvesting is already implemented in few countries. Pest control system using artificia intelligence is getting implemented in few places. The work which we have proposed here, is to help the farmers to test the soil sample and let them know what is lacking in it by analyzing soil fertility and what has to be added to increase soil fertility, also this work aims to recommend the crops which can be suitably grown from given soil sample. This is going to help our Indian farmers to understand about the soil in an easier and better way and take further steps to grow crops in an efficient way. This will surely reduce the defective crops and promote healthy crops. There are soil sensors which are available in market which senses the soil like PH, Nitrogen, Potassium, Phosphorous, moisture content and humidity are used to find the fertility of soil. Using Deep learning ,a technique of artificial intelligence , the system will be trained in such a way that the soil fertility and its crop friendliness is detected .IOT features along with AI technique will increase the soil testing and monitoring efficiency.

\section{B.Artificial Intelligence in IT for soil testing}

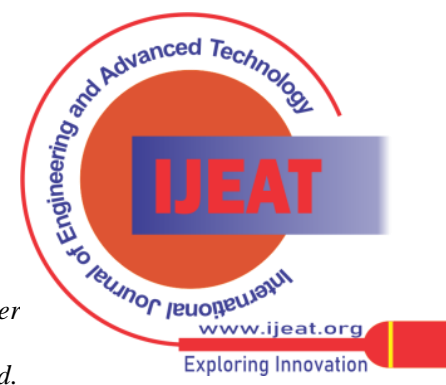


Companies are even trying out to create chat-bots like Alexa to lessen the work of farmers, Microsoft in collaboration with ICRISAT has brought up AI sowing App powered by Microsoft Cortana Intelligence Suite having ML and Power $\mathrm{BI}$ to convey the farmers the right time to sow so that their yield can be maximized. IBM AgroPad is one prototype solution which is developed by Brazil researchers where a paper testing strip ( chemical chip containing micro fluids meant for performing chemical analysis of soil and water) with mobile app is proposed which is dependent on machine vision technique to say the amount of chemicals present in the soil sample[9]. PEAT-Berlin based start-up working on agricultural technology has come up with deep learning Application known as Plantix meant for finding nutrient deficiencies of soil where Algorithms are being used which will correlate particular foliage patterns with certain soil defects, plant pests and diseases. A system cable of detecting strength and weaknesses of soil with the help of ML has been brought up by Lead investor Illumina aiming at producing healthy crop and preventing defects in growth. SkySquirrel Technologies Inc. company has started introducing drone technology to vineyards[10]

\section{ARCHITECTURE OF THE PROPOSED SYSTEM}

Deep learning ,a kind of Artificial neural network(ANN) is an Artificial Intelligence technique and this is the key area selected for the proposed work, Deep learning , An ANN has collection of connected units called as artificial neurons which actually works like neurons of human brain. Each neuron receives the signal from its previous neuron and transfers the signal to another neuron connected to it, the output of each neuron is computed by some non-linear function of the sum of its inputs called wights. As learning happens the neurons and connections will have updated weights. The weight may increases or decreases depending on the . The neurons will be kept in layers. Different layers may perform different transformations on their inputs. Signals travel from the input layer, to the output layer. like human brain ,it incorporates Human like reasoning ability by the help of algorithms written for any specific application. Deep learning has an ability to learn itself without human supervision.

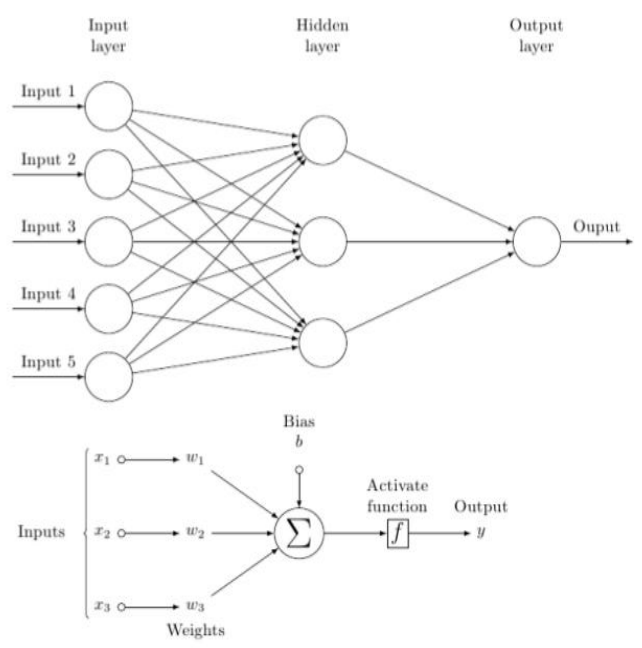

Fig. 1:Deep learning network

Soil sensors are the devices used to capture the soil parameters which can be given as input to the system, soil sensors can be used to read the values of $\mathrm{pH}$, moisture content, temperature, NPK to the system for processing. Soil sensors play vital role in precision agriculture .

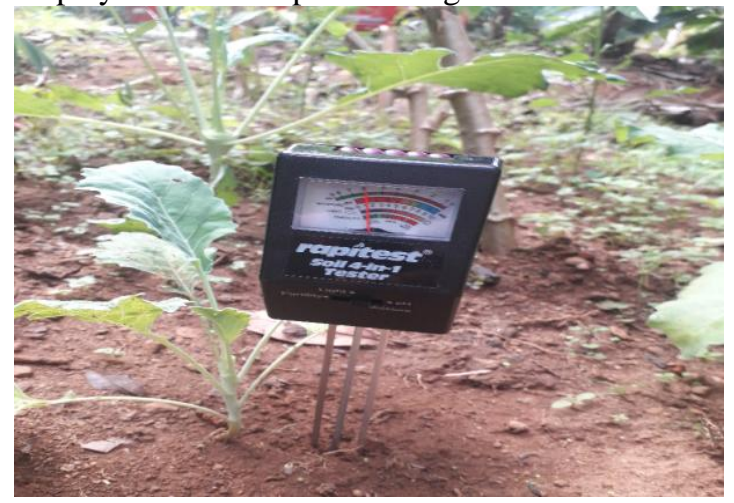

Fig. 2:Soil sensors used for testing parameters

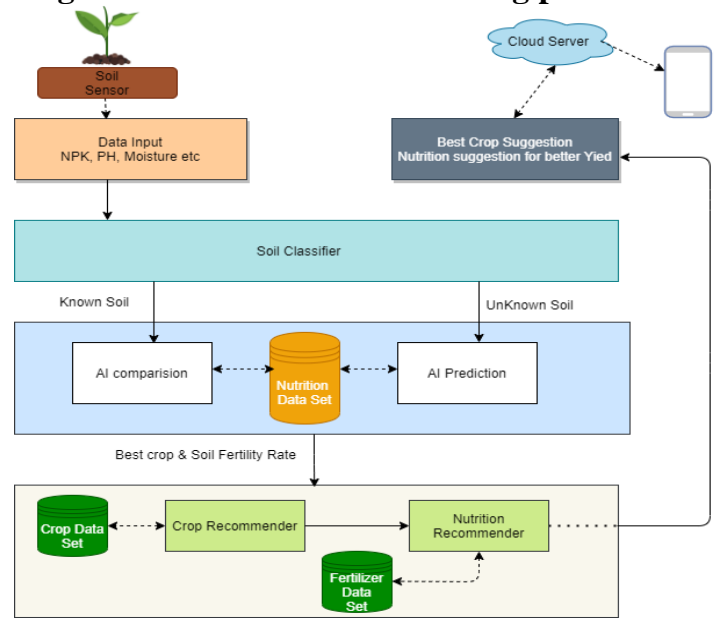

Fig. 3: The architecture of the proposed system

\section{The soil classifier Module}

The 'soil classifier' module takes the input from user interface and classifies the user data as known soil type or unknown soil type which will be next transferred to the necessary module for further processing. User interface can be developed and integrated with this module to provide necessary user inputs to the system. If the user input is known soil type, The control is transferred to AI comparison module else if the user input is unknown soil type, the control is transferred to AI prediction module.

\section{The AI comparison Module}

AI comparison module uses 'Nutrition data set',Nutrition data set contains soil parameters data like NPK, $\mathrm{pH}$, moisture content, humidity, temperature, organic matter, other micro and macro nutrients . AI comparison module compares the data given against the older dataset stored in nutrition dataset and tells the fertility rate of the given samples. This would help farmers to know and understand the quality of the soil and ensure about successful crop growth there by decrease the struggle of farmers.

\section{E. The AI Prediction Module}

The AI prediction module also uses nutrition data set, nutrition data set contains soil parameters data.

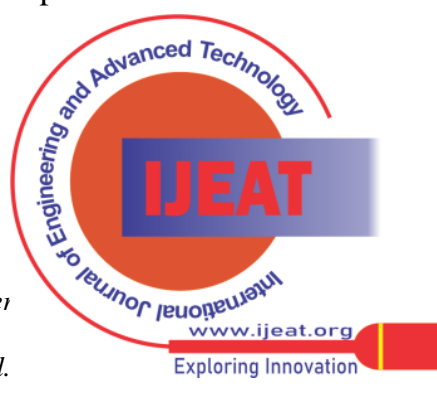




\section{An AI solution for Soil Fertility and Crop Friendliness Detection and Monitoring}

AI prediction module also predicts the fertility of the soil sample given and suggests the best crop which can be grown out of the given soil sample. If the farmer is recommended with the best crop which he can grow, most of the vulnerabilities caused after growing the irrelevant crops can be prevented. This facilitates healthy crop harvest.

\section{The Crop Recommender}

The soil fertility rate and best crop prediction given from the previous module is used for suggesting top five crops from 'Crop Recommender' module . Crop Recommender uses crop dataset which has soil parameters, crop suggestions and crop related information. Crop Recommender suggests the best five crops which can be grown from the given sample. Top Crop suggestions help farmers to choose the crops which is more relevant to his needs and facilities. This also increases the productivity.

\section{E. The Nutrition Recommender}

The nutrients or required fertilizers needed for all the crops are suggested by 'Nutrition Recommender' module. It uses crop dataset along with the output of Crop Recommender. The nutrients required for the suggested crops will help the farmer to enhance the fertility and increase the yield. Suggesting the nutrients for all the crop suggestions would be a great help for farmers. The results of soil testing, crop and fertilizer recommendations are stored in cloud and sent to farmers to his phone in easily readable and understandable format . So this shows IOT feature along with Deep learning technique.

\section{DATASET}

Since Agriculture data is vast in nature, we have been collecting data from few places of Bhagamandala region of Madikeri,Kodagu targeting coffee growing soil , so that particular soil type like coffee growing soil , would be easier for implementation and testing. The soil type of Kodagu is mostly laterite and some part having fertile red loamy soil and alluvial soil, with great rainfall and having temperature between $14{ }^{\circ} \mathrm{C}-29^{\circ} \mathrm{C}$. All these features facilitates the growth of coffee, pepper, cardamom, banana, ginger, paddy, cashew, Arecanut, rubber, orange, some vegetables. Some data has also been collected from on line .Data is stored in CSV format.

Nutrition dataset of coffee growing soil would look like \{coffee_sample_no, coffee_type,Yield,Place, pH, Nitrogen, Phosphorous, Potassium, Moisture, humidity, organic_carbon ,temperature, rainfall,season, soil_type \} Fertilizer dataset of coffee growing soil would include \{coffee_sample_no,coffee_type, pH,NPK,Lime_recommendation,season,soil_type,N20, P20,K20,urea,fertilizer,mop,Mixture_per_plant,organic_mat ter

Table- I: Sample(a part of ) Nutrition dataset of coffee growing soil stored in CSV file.

\begin{tabular}{|l|l|l|l|l|l|l|l|}
\hline $\begin{array}{l}\text { coffee } \\
\text { samp } \\
\text { le_no }\end{array}$ & $\begin{array}{l}\text { Coffee_ } \\
\text { type }\end{array}$ & Place & Yield & $\mathrm{pH}$ & $\begin{array}{l}\text { Phosphor } \\
\text { ous }\end{array}$ & $\begin{array}{l}\text { Potassiu } \\
\mathrm{m}\end{array}$ & season \\
\hline 1 & $\begin{array}{l}\text { Robust } \\
\text { a }\end{array}$ & $\begin{array}{l}\text { Thavo } \\
\text { or }\end{array}$ & 350 & 5.7 & 6 & 160 & $\begin{array}{l}\text { Post } \\
\text { mansoo } \\
\mathrm{n}\end{array}$ \\
\hline
\end{tabular}

\begin{tabular}{|l|l|l|l|l|l|l|l|}
2 & $\begin{array}{l}\text { Robust } \\
\text { a }\end{array}$ & $\begin{array}{l}\text { Thavo } \\
\text { or }\end{array}$ & 380 & 5.5 & 6 & 190 & $\begin{array}{l}\text { Pre- } \\
\text { mansoo } \\
\mathrm{n}\end{array}$ \\
\hline 3 & $\begin{array}{l}\text { Arabic } \\
\text { a }\end{array}$ & $\begin{array}{l}\text { Thavo } \\
\text { oru }\end{array}$ & 600 & 6.6 & 24 & 248 & $\begin{array}{l}\text { Post- } \\
\text { blosso } \\
\text { m }\end{array}$ \\
\hline
\end{tabular}

\section{ADVANTAGES OF THE PROPOSED WORK}

1. Soil quality can be known which facilitates healthy crop growth.

2. Since the best crops are suggested, this would help the farmers to choose the right crops according to his facilities and needs.

3. Since fertilizers or nutrients are recommended for all the crop suggestions, this will help the farmers to get the proper knowledge to grow the crops and enhance the productivity and income.

4. Our proposed system works with minimum hardware implementation, and there is no battery requirement like other systems.

5. Since AI has power to learn on its own, Proposed system can test any soil sample,so this system can be considered robust method for soil testing.

6. AI is intended to provide precise and more accurate result with minimum delay, so this could be considered an efficient approach for soil testing.

7. The testing and recommendation results can be sent to farmers phone in an understandable format so user friendly and timely reports are also the great merits of the proposed system.

8. This approach could be a cost efficient and easily accessible solution for farmers

\section{CONCLUSION}

The proposed work involves use of Deep learning ,an Artificial Intelligence technique along with IOT features which could be a contribution to the field of precision agriculture. The proposed work helps the farmers in various dimensions by letting them know the necessary nutrients required to increase the fertility of the soil thus helping them increase the overall yield. It is also going to help farmers to hoose the right crops also recommends the top 5 crops which are most suitably grown in his land and also way to increase the fertility of all suitably grown crops are suggested

\section{REFERENCES}

1. Liu Hui1,Wang Mao-hua1,Wang Yue-Xuan2,Ma Dao-kun1,Li Haixia1, " Development of farmland soil moisture and temperature monitoring system based on wireless sensor network" Journal of jillin University.

2. Purvi Mishra , Sudha Mapara and Preeti Vyas,"Testing/Monitoring of Soil Chemical Level Using Wireless Sensor Network Technology" IJAIEM

3. Dr. T. Venkat Narayana Rao S. Manasa "Artificial Neural Networks for Soil Quality and Crop Yield Prediction using Machine Learning"

4. International Journal on Future Revolution in Computer Science \& Communication Engineering.

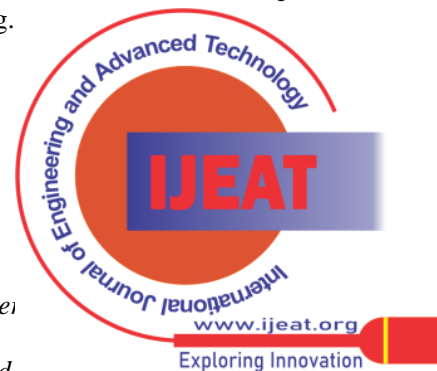


5. Ji-chun Zhao Jian-xin Guo , "Big Data Analysis Technology Application in Agricultural Intelligence Decision System" 2018 IEEE conference on cloud computing \&Big data analysis

6. S.Pudumalar,E.Ramanujam,R.HarineRajashreeń,C.Kavyań,T.Kiruthi kań,J.Nisha "Crop Recommendation System for Precision Agriculture" 2016 IEEE(ICoAC)

7. Amrutha A, Lekha R, A Sreedevi “ Automatic Soil Nutrient Detection and Fertilizer Dispensary System” 2016 International Conference on Robotics(RTCFC)

8. Balmukund Maurya, Prof. Dr. Mohd Rizwan Beg ,Sudeep Mukherjee "Expert System Design And Architecture For Farming Sector Proceedings of 2013 IEEE.

9. https://www.zdnet.com/article/ibm researchers-help-small-farmerstest-soil-with-ai/

10. https://emerj.com/ai-sector-overviews/ai-agriculture-present-applicati

\section{AUTHORS PROFILE}

Varshitha D $\mathbf{N}$ is a full-time research Scholar doing her PhD at Dept of CSE, SirMVIT Bengaluru ,She has obtained her Mtech(CSE)from VTU, Karnataka

(A) Dr. Savita Choudhary working as a Associate. Professor at a Dept. of CSE, Sir MVIT, Bengaluru. She has obtained her PhD from Bhagwanth University, Ajmer. She has expertise in the area of soft computing, Dr Savita has published papers in several international conferences and journals, she has also guided many research scholars. 